\title{
Preface for Thematic Section: Green Rare Earth Elements- Innovations in Ore Processing, Hydrometallurgy, and Electrolysis
}

\author{
B. Friedrich ${ }^{1}$ (D)
}

Published online: 1 November 2016

(C) The Minerals, Metals \& Materials Society (TMS) 2016

Rare earth elements (REEs) can be obtained from both natural resources and by recycling. Currently, more than $95 \%$ of the global demand are mined and processed into rare earth metals in China. The demand for REEs for applications in the high-tech sector will increase steadily in the future. Hence, the supply chain of the western industries is entirely dependent on imports. Due to this uncertainty, it is of high economic and social interest to identify alternative supply structures for REEs. The aim of many ongoing research projects around the globe is the identification of new supply chains. In addition, innovative and sustainable methods for their implementation are developed within these projects. While dealing with these issues, it is crucial to consider the superordinate economic, environmental, and social aspects. Currently, the recycling of post-consumer-waste ("old scrap") accounts for only $1 \%$ to the supply with REEs. The extent, to which post-production-waste ("new scrap") is recycled, is currently not reported. Europe, Japan, and the US are increasing their activities in tapping new primary and secondary resources in order to raise their raw material potential.

The contributing editor for this article was Yiannis Pontikes.

B. Friedrich

bfriedrich@ime-aachen.de

1 Department of Process Metallurgy and Metal Recycling, RWTH Aachen University, Intzestr. 3, 52056 Aachen, Germany

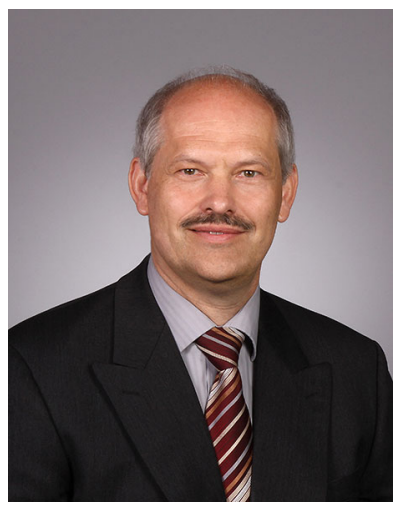

In order to illustrate the holistic examination that the ongoing research projects have provided so far, this thematic section "Green REEs-innovations in ore processing, hydrometallurgy and electrolysis" in the Journal of Sustainable Metallurgy was launched. The goal of all the research work presented within is the investigation of methods and procedures to ensure the sustainable supply with REEs. The predominantly technically oriented research projects as a whole cover the entire process chain. Topics addressed range from the exploitation of REEs from alternative deposits or by recycling of process waste, to the processing of ores, their extraction, and metallurgical refining and the processing of rare earth metals by electrolysis. Regarding the exploitation of deposits, a structured assessment and evaluation of deposits is examined. Within the research on the mining of REEs, treatment processes enabling the reduction of consumables-especially energy and chemicals-and process wastes for disposal are investigated. Another emphasis within the research of REE mining is the possibility to reduce the risk of accompanying radioactive elements. In addition, the potential for recycling of process waste and post-consumer- 
waste is investigated. The technical feasibility of processing and recycling process waste from the production of $\mathrm{NdFeB}$-magnets is examined. Nevertheless, in order to develop a supply chain independent from China, countryspecific location factors such as current environmental standards and social conditions have to be taken into account, when assessing the economic feasibility of the presented investigations in future.

A significant part of the articles originate from the SIEMENS Collaborative Rare Earth Research Center
"Green Mining and Separation," which was run from 2012 to 2015 at RWTH Aachen University. We have chosen several articles from the open workshop during the International Conference on Rare Earths, held in November 2015 in Singapore. Finally, I would like to acknowledge that this thematic section would not have been possible without the strong engagement of Bart Blanpain and Shinya Kitamura, acting as handling editors for all the papers I co-authored. 